\title{
Analysis, Design and Implementation of Human Fingerprint Patterns System "Towards Age \& Gender Determination, Ridge Thickness To Valley Thickness Ratio (RTVTR) \& Ridge Count On Gender Detection
}

\author{
${ }^{1}$ E.O. OMIDIORA, ${ }^{2}$ O. OJO. \\ ${ }^{1,4}$ Dept Of Computer Science \& Engineering \\ 14Ladoke Akintola University of Technology \\ 14Ogbomosho Nigeria
}

\author{
${ }^{3}$ N.A. YEKINI, ${ }^{4}$ T.O. TUBI \\ ${ }^{2,3}$ Dept Of Computer Technology \\ Yaba College of Technology \\ Yaba Lagos Nigeria
}

\begin{abstract}
The aim of this research is to analyze humans fingerprint texture in order to determine their Age \& Gender, and correlation of RTVTR and Ridge Count on gender detection. The study is to analyze the effectiveness of physical biometrics (thumbprint) in order to determine age and gender in humans. An application system was designed to capture the finger prints of sampled population through a fingerprint scanner device interfaced to the computer system via Universal Serial Bus (USB), and stored in Microsoft SQL Server database, while backpropagation neural network will be used to train the stored fingerprint. The specific Objectives of this research are to: Use fingerprint sensor to collect different individual fingerprint, alongside their age and gender, Formulate a model and develop a fingerprint based identification system to determine age and gender of individuals and evaluate the developed system.
\end{abstract}

Keywords: Age; Gender; Fingerprint; Ridges Count; RTVTR.

\section{INTRODUCTION}

A Fingerprint is the representation of the epidermis of a finger; it consists of a pattern of interleaved ridges and valleys. Fingertip ridges evolved over the years to allow humans to grasp and grip objects. Like everything in the human body, fingerprint ridges form through a combination of genetic and environmental factors. This is the reason why even the fingerprint of identical twins is different (Maltoni and Cappelli, 2006).

The concept of fingerprint pattern being studied has been of significant use over time, when scanning it involves the conversion of fingerprint by small portion of light solid-state devices into alphanumeric formula (Glaton, 1982).

The technology of using human body for identification purpose is known as "Biometrics", the word was derived from Greek word meaning Bio for "life" and Metric for "Measurement", the authentication of biometrics for personal identification is extremely and more reliable compared with something you know which can be forgotten (like password, registration numbers) or what you have (like identity card, physical lock, smart card) which can be misplaced compared with something you are or parts of your body. (Neil and Adnan 2004).

Biometrics measures the unique physical or behavioral characteristics of individual as a means to recognize or authenticate their identity. Common physical biometrics includes fingerprints, hand or palm geometry, and retina, iris or facial characteristics. Behavioral characteristics include signature, voice (which also has a physical component), keystroke pattern and gait. Although some technologies have gained access control and biometrics as a whole shows great potential for use in end user segments, such as airports, stadiums, defense installations and the industry and corporate workplaces where security and privacy are required (Jain et al 2003).

\section{LITERATURE REVIEW}

\section{A. Overview of Fingerprinting}

Human fingerprints have been discovered on a large number of archeological artifacts and histological items. Although these findings provide evidence to show that ancient people were aware of the individuality of fingerprints, it was not until the late sixteenth century that the modern scientific fingerprint technique was first initiated (Jain, et al, 2003). In 1686, Marcello Malpighi, a professor of anatomy at the University of Bologna noted in his writings the presence of ridges, spirals and loops in fingerprints. Since then, a large number of researchers have invested huge amounts of effort on fingerprint studies (Gu, Zhou, and Yang, 2006).

Henry Fauld, in 1880, was the first to scientifically suggest the individuality of fingerprints based on an empirical observation. At the same time, Herschel asserted that he had practiced fingerprint recognition for about 20 years. These findings established the foundation of modem fingerprint recognition. In the late nineteenth century, Sir Francis Galton conducted an extensive study on fingerprints; he introduced the minutiae features for fingerprint matching in 1888. An important advance in fingerprint recognition was made in 1899 by Edward Henry, who established the well-known 
Henry system" of fingerprint classification (Lee and Gaensslen, 2001).

In the early twentieth century, fingerprint recognition was formally accepted as a "valid personal identification method and became a standard routine in forensics (Lee and Gaensslen, 2001). Fingerprint identification agencies were set up world-wide and criminal fingerprint databases were established (Lee and Gaensslen, 2001).

Various fingerprint recognition techniques, including latent fingerprint acquisition, fingerprint classification and fingerprint matching were developed. For example, the FBI fingerprint identification division was set up, in 1924, with a database of 810,000 fingerprint cards (Federal Bureau of Investigation, 1984).

European explorer Joao de Barros recorded the first known example of fingerprinting, which is a form of biometrics, in China during the 14th century. Chinese merchants used ink to take children's fingerprints for identification purposes. In 1890, Alphonse Bertillon studied body mechanics and measurements to help in identifying criminals. The police used his method, the Bertillon age method, until it falsely identified some subjects. The Bertillon age method was quickly abandoned in favor of fingerprinting, brought back into use by Richard Edward Henry of Scotland Yard. Karl Pearson, an applied mathematician studied biometric research early in the $20^{\text {th }}$ century at University College of London. He made important discoveries in the field of biometrics through studying statistical history and correlation, which he applied to animal evolution. His historical work included the method of moments, the Pearson system of curves, correlation and the chi-squared test.

In the 1960s and '70s, signature biometric authentication procedures were developed, but the biometric field remained fixed until the military and security agencies researched and developed biometric technology beyond fingerprinting (Caplan and Dermatol. 1990).

Since $700 \mathrm{AD}$, this science of fingerprint has been used for the purpose of identification. Chinese used fingerprints as official documents in 3000BC. The system was first used in India in 1858 by Sir William Herschel to prevent impersonation, but the credit is given to Sir Francis Galton for having it systematized for the identification of criminals. His system was officially adopted in England in 1894, and was further modified by Sir Edward Henry. Afterwards the studies have been conducted on fingerprint ridges mainly its types, classification, methods of lifting fingerprints, recording of fingerprints and materials used to develop fingerprint (Gungadin 2007).

Fingerprint identification and classification has been extensively researched in times past, however very few researchers have studied the fingerprint gender classification problem, (Acree 1999) used the ridge density, which he defined as the number of ridges in a certain space; it was shown that the females have higher ridge density (Acree 1999). (Kralik 2003) also showed that the males have higher ridge breadth,) which was defined as the distance between the centers of two adjacent valleys), than females.
Two studies showed that the males have higher ridge count than the females (Hall, Timura 2003) and (Cote, Earls, Lalumiere 2002). It was shown that both males and females have higher rightward directional asymmetry in the ridge count, with the asymmetry being higher in males than females (Hall and Kimura 2003), and higher incidence of leftward asymmetry in females. (Cote et al 2002). Female's fingerprints are significantly of lower quality than male fingerprints (Hicklin and Reedy. 2002). While the appearance of white lines and scars in fingerprint images are very common in housewives (Wendt 1955).

By the seventh month of natal development, the dermatoglyphic patterns of the fingers are complete and no further modifications can occur during maturation except in the case of accident. Since, during growth, the overall size of the palm increases, the fingerprint increase in size without adding new ridges and ridge breadth this is defined as the measurement from the center of one furrow across the ridge to the center of the next furrow. (Penrose 2001)

Within individual, the breadth of fingerprint ridge varies within the hand and between hands, but the difference is quite small, on the order of $0.05 \mathrm{~mm}$ and less (Cummings 1994).

Although it has been found that males tend to have more ridge counts than females, inconsistent results have been obtained with regard to the statistical significance of this sex difference. It has also been shown that women tend to have a higher ridge density (ridge counts divided by the size of the corresponding fingertip area) than men but the sex determination accuracy of this feature does not seem to be very satisfactory (Acree 1999).

The female's fingerprint is characterized by a high Ridge Thickness Valley Thickness Ratio, while the male's fingerprint is characterized by low Ridge Thickness Valley Thickness Ratio, with the exception of small percentage of male's fingerprints having high Ridge Thickness Valley Thickness Ratio, and female's fingerprints having low Ridge Thickness Valley Thickness Ratio (Baldawi et al. 2008)

The female's fingerprint is characterized by high count of white lines, with the exception of small percentage having few or no white lines. The male's fingerprint is characterized by having no or few number of white lines, with the exception of small percentage having high count of white lines also that the male's ridge count is slightly higher than the female's, with high standard deviation in its distribution among both genders, ridge count for the females, with $\mu=13.6671, \sigma=4.9845$, and the males, with $\mu=14.6914, \sigma=4.9336$, with $\mathrm{t}$-value $=4.802$, and $\rho$-value $=1.685 \mathrm{E}-06$ (Badawi et al. 2008)

The size of the fingertip has a strong relationship to the values of ridge counts and ridge density. If males have more ridge counts and smaller ridge densities than females, then the finger size difference between males and females should be more significant than the features of ridge count and ridge density (Wang et al 2007).

Gungadin (2007) opined that a ridge count of $\leq 13$ ridges $/ 25 \mathrm{~mm} 2$ is more likely to be of male origin and that of $\geq 14$ ridges $/ 25 \mathrm{~mm} 2$ is likely to be of female origin. The 
outcome of his study is that women tend to have more ridge density than men.

\section{B. Fingerprint Classification}

Fingerprint identification and verification are one of the most significant and reliable identification methods. It is virtually impossible that two people have the same fingerprint, having a probability $1 / 1.9 \times 10^{15}$ (Hong et al. 2000). In fingerprint identification and verification applications worldwide, a large volume of fingerprints are collected and stored for a wide range of applications, including forensics, civilian, commercial and law-enforcement applications.

Automatic identification of humans based on fingerprints requires the input fingerprint to be matched with a large number of fingerprints in a database (for example, the FBI database contains approximately 70 million fingerprints). To reduce the search time and computational complexity, it is desirable to classify the database into accurate and consistent classes so that input fingerprint is matched only with a subset of the fingerprints in the database. The nature of each application will determine the degree of accuracy required. For example, a criminal investigation case may require higher degree match than access control case systems.

Automatic fingerprint classification methods, such as methods introduced in (Drets and Liljenstrom, 1999) rely on point patterns in fingerprints, which form ridge endings and bifurcation unique to each person.

Traditionally, activities to solve a pattern recognition task are twofold. First, a set of features has to be found describing the object(s) being classified. Second, after a set of features has been found, a classification mechanism is chosen and optimized. These two steps are highly interdependent, since the choice of features influences the conditions under which a classifier operates, and vice versa. (Mohamed, Nyongesa and Siddiqi 2002).

With the advent of neural networks however, more and more problems are solved by simply feeding large amounts of 'raw data' (e.g. images, sound signals, stock market index ranges) to a neural network. This approach, however, is not feasible in fingerprint classification, which are highly susceptible to noise and elastic distortions. Therefore, it is desirable to extract features from the images that are invariant to such distortions. During training the classification network learns the association and significance of features. An attempt has been made previously to study fuzzy logic and artificial neural network techniques in fingerprint identification. (Mohamed, Nyongesa and Siddiqi 2002).

\section{Fingerprint Feature Extraction (FFE)}

The central problem in designing a fingerprint classification system is to determine what features, should be used and how categories are defined based on these features. There are, mainly two types of features that are useful for fingerprint recognition system: (i) Local ridge and valley details (minutiae) which have different characteristics for different fingerprints, and

(ii) Global pattern configurations, which form special patterns of ridges and valleys in the central region of the fingerprint.

The first type of features carries for the information about the individuality of fingerprints and the second type of features carry information about the fingerprint class. Therefore, for fingerprint classification, the features derived from the global pattern configurations should be used. These features should be invariant to the translation and rotation of the input fingerprint images. Generally, global fingerprint features can be derived from the orientation field and the global ridge shape. The orientation field of a fingerprint consists of the ridge orientation tendency in local neighborhoods and forms an abstraction of the local ridge structures. It has been shown that the orientation field is highly structured and can be roughly approximated by the core and delta models (Monro and Sherlock, 1993) which are known as singular points details.

\section{METHODOLOGY}

\section{A. Fingerprint Acquisition}

The ten fingerprints of two hundred individual was collected, one hundred male and one hundred females for different age groups. The age group was divided in series of five years (i.e. $0-5,6-10,11-15,16-20,21-25 \ldots \ldots$. ). The captured fingerprint was stored in a Microsoft SQL Server database through an interfaced fingerprint reader.

\section{B. CREATING THE APPLICATION}

The application was created using Microsoft Visual Studio 2008 integrated development environment (IDE). Visual Studio .NET is Microsoft's integrated development environment (IDE) for creating, documenting, running and debugging programs written in a variety of .NET programming languages. Visual Studio .NET also offers editing tools for manipulating several types of files. Visual Studio .NET is a powerful and sophisticated tool for creating business-critical and mission-critical applications. Figure 1 shows Microsoft Visual Studio .Net 2008 IDE environment. $\mathrm{C \#}$ is the ideal language used for the development of the application.

Figure 2 shows the runtime environment of the application. The first page shown here is Data Collection/Identification page. Data collection involve collection of fingerprint, sex and age range of different people. "Save button" will be clicked in other to save the data into the database. This will then trigger the fingerprint reader to ask for thumb. Clear button can be used to clear the data in other to save another one.

Before identification, the network must be trained properly in other to give better result. Train Network button can be used to train the network, while Load Network button can be used to load the already trained network. 


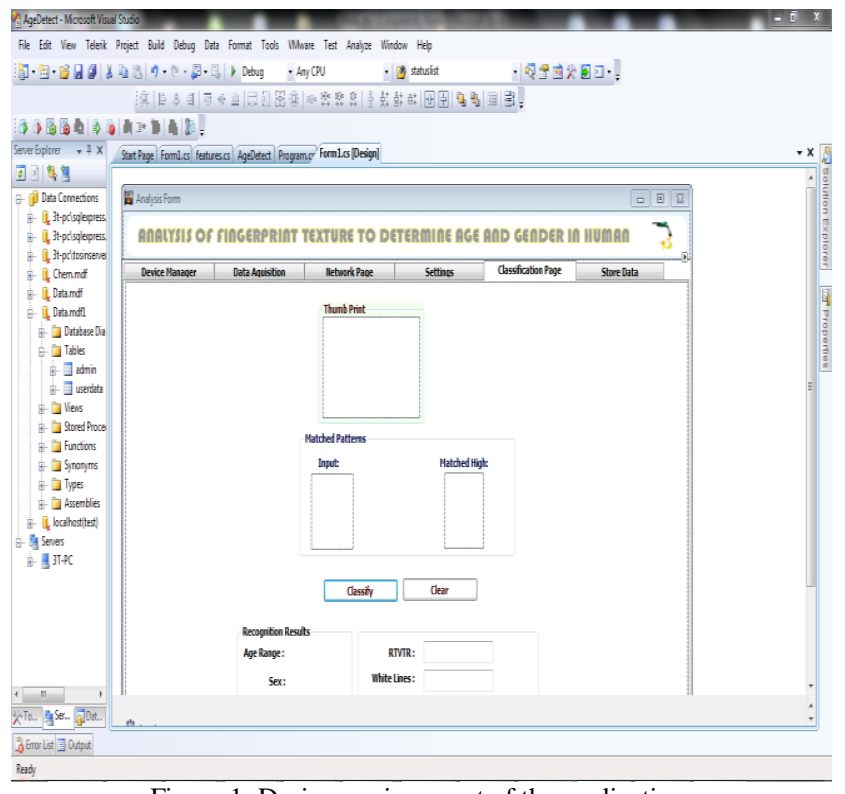

Figure 1: Design environment of the application.

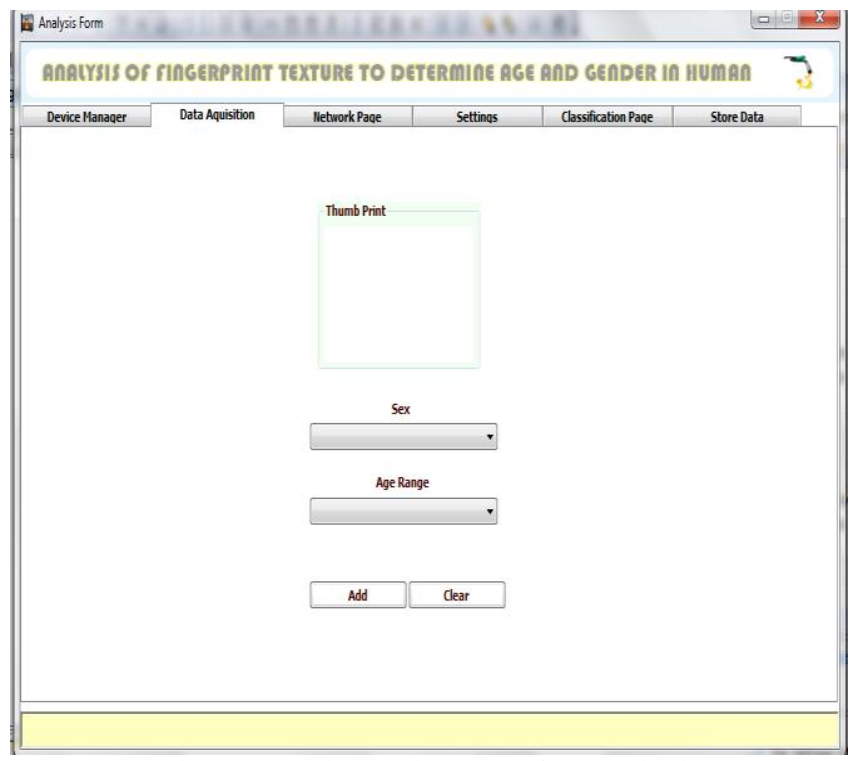

Figure 2: Runtime environment of the application.

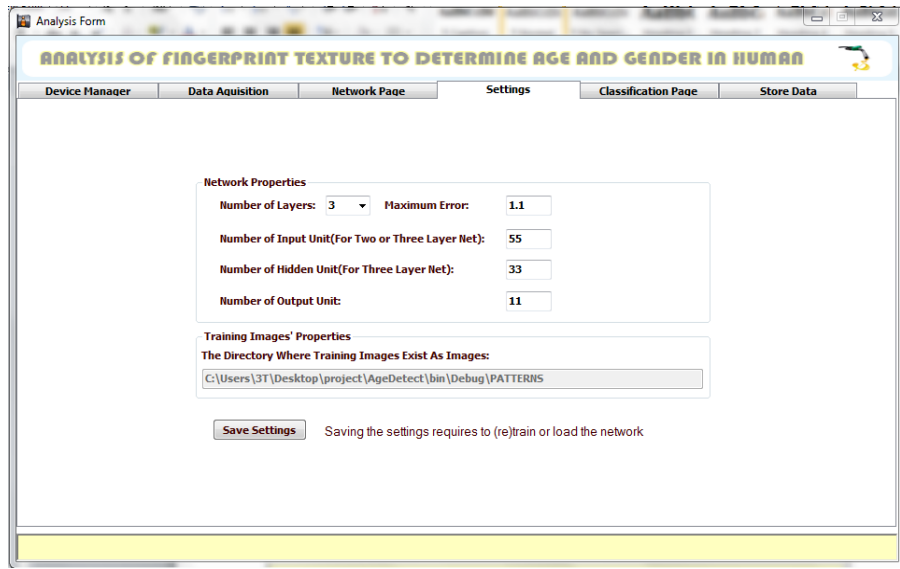

Figure 3: Network Settings Form.
Figure 3 shows the required network properties. The flowchart for the methodology is as shown below:

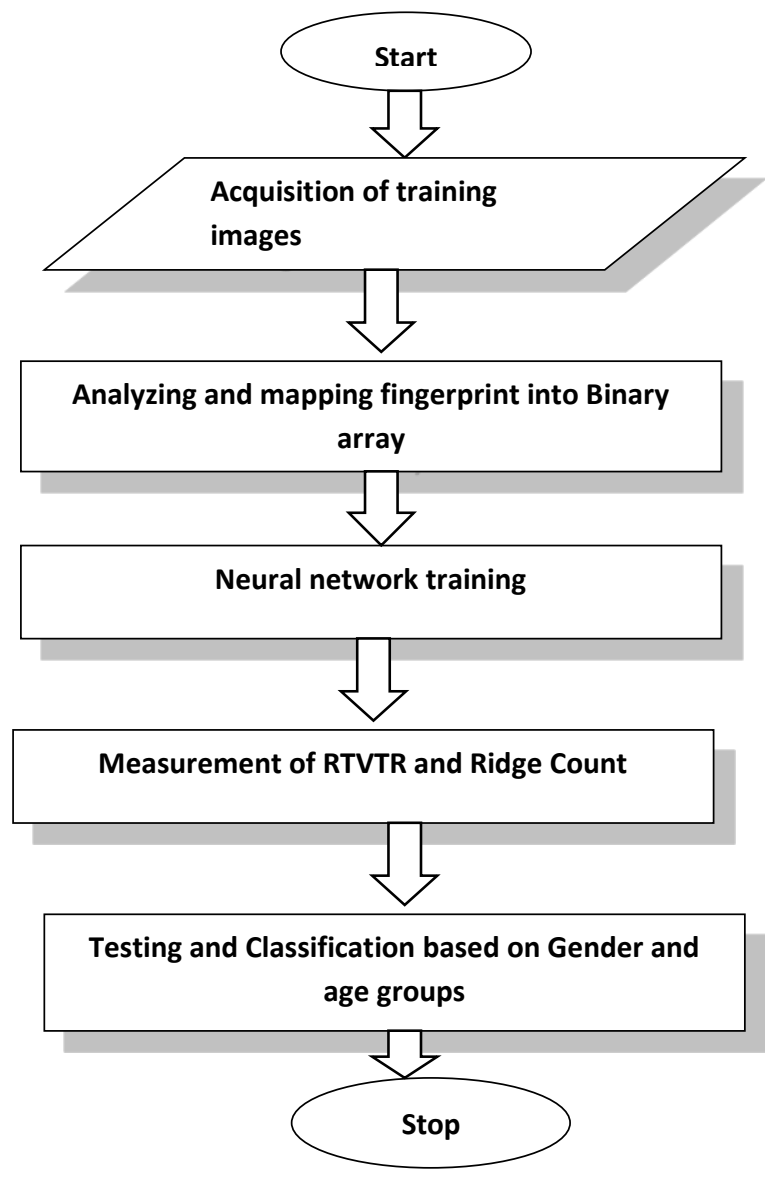

FLOWCHART FOR METHODOLOGY

IV. IMPLEMENTATION AND DISCUSSION

A. Analysis of Results

Having trained the network and used some samples of fingerprint to predict the gender and age range of some some individuals. The following results were obtained.

TABle 1: Results OF AgE AND GENDER PREDICTION.

\begin{tabular}{|c|c|c|c|c|c|c|}
\hline $\mathrm{S} / \mathrm{N}$ & $\mathrm{AG}$ & $\mathrm{EG}$ & $\mathrm{AA}$ & $\mathrm{EA}$ & $\mathrm{GC}$ & $\mathrm{AC}$ \\
\hline 1 & $\mathrm{M}$ & $\mathrm{M}$ & $21-25$ & $26-30$ & YES & NO \\
\hline 2 & $\mathrm{M}$ & $\mathrm{F}$ & $26-30$ & $26-30$ & NO & YES \\
\hline 3 & $\mathrm{~F}$ & $\mathrm{~F}$ & $26-30$ & $26-30$ & YES & YES \\
\hline 4 & $\mathrm{M}$ & $\mathrm{M}$ & $21-25$ & $26-30$ & YES & NO \\
\hline 5 & $\mathrm{M}$ & $\mathrm{M}$ & $26-30$ & $26-30$ & YES & YES \\
\hline 6 & $\mathrm{~F}$ & $\mathrm{M}$ & $26-30$ & $26-30$ & NO & YES \\
\hline 7 & $\mathrm{M}$ & $\mathrm{M}$ & $21-25$ & $26-30$ & YES & NO \\
\hline 8 & $\mathrm{~F}$ & $\mathrm{~F}$ & $21-25$ & $16-20$ & YES & NO \\
\hline 9 & $\mathrm{~F}$ & $\mathrm{~F}$ & $26-30$ & $26-30$ & YES & YES \\
\hline 10 & $\mathrm{M}$ & $\mathrm{M}$ & $26-30$ & $16-20$ & YES & NO \\
\hline
\end{tabular}




\begin{tabular}{|c|c|c|c|c|c|c|}
\hline 11 & F & F & $16-20$ & $26-30$ & YES & NO \\
\hline 12 & M & F & $21-25$ & $26-30$ & NO & NO \\
\hline 13 & F & F & $21-25$ & $26-30$ & YES & NO \\
\hline 14 & M & M & $26-30$ & $16-20$ & YES & NO \\
\hline 15 & M & M & $21-25$ & $26-30$ & YES & NO \\
\hline
\end{tabular}

TABLE 2: PERCENTAGE ACCURACY OF THE MODEL, WHERE AG $=$ ACTUAL AGE, EG = EXPERIMENTAL AGE, AG = ACTUAL AGE, $\mathrm{EA}=$ EXPERIMENTAL AGE, GC $=$ GENDER CORRELATION AND $\mathrm{AC}=$ AGE CORRELATION

\begin{tabular}{|c|c|}
\hline GENDER ACCURACY & $\begin{array}{c}\text { AGE } \\
\text { ACCURACY }\end{array}$ \\
\hline $80.00 \%$ & $33.33 \%$ \\
\hline
\end{tabular}

From the table above, the percentage accuracy of the model for age is $33.3 \%$ while that of gender is $80 \%$.

\section{B. Ridge Thickness To Valley Thickness Ratio}

Measuring the Ridge thickness to valley thickness ratio (RTVTR), the following results were obtained for 15 randomly selected samples.

The result shows that the females have a higher RTVTR compared to the males.

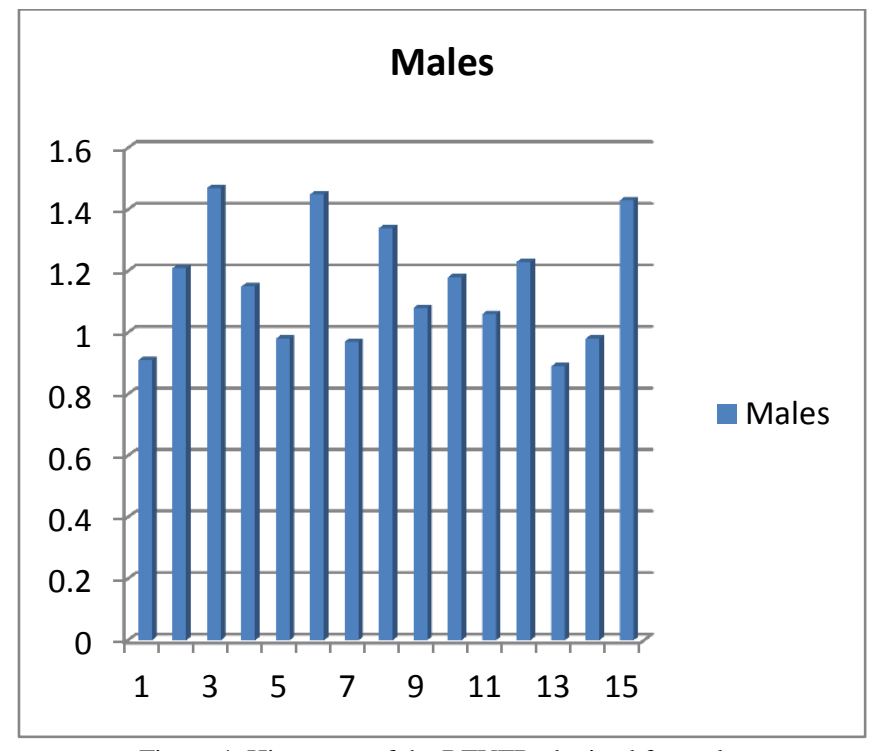

Figure 4: Histogram of the RTVTR obtained for males

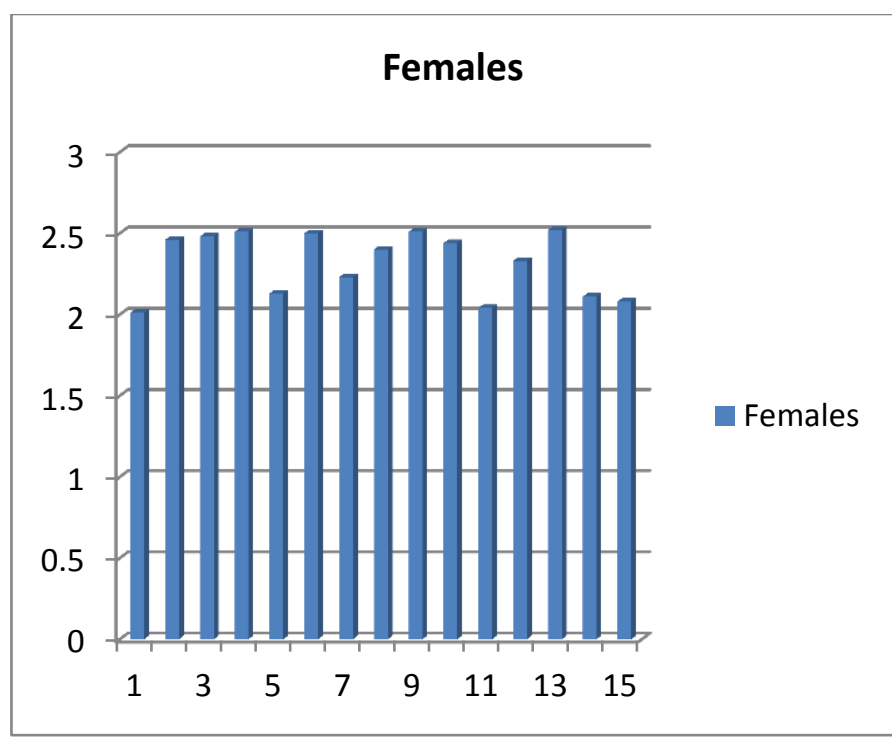

Figure 5: Histogram of the RTVTR obtained for females

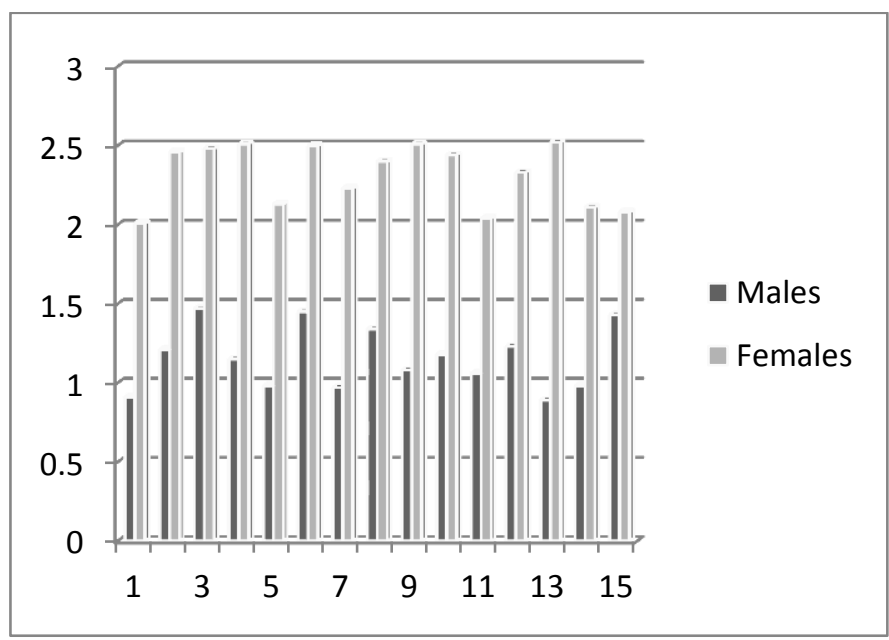

Figure 5: Histogram for the RTVTR obtained for females versus the males

TABle 4: Mean, Standard DeViation and Variances FOR the Result OBTAINED

\begin{tabular}{|c|c|c|c|}
\hline & Mean & S.D & Variance \\
\hline Males & 1.155 & 0.191 & 0.0353 \\
\hline Females & 2.310 & 0.188 & 0.0363 \\
\hline
\end{tabular}

TABLE 3: RTVTR RESULT

\begin{tabular}{|c|c|c|c|c|c|c|c|c|c|c|c|c|c|c|c|}
\hline $\mathrm{S} / \mathrm{N}$ & 1 & 2 & 3 & 4 & 5 & 6 & 7 & 8 & 9 & 10 & 11 & 12 & 13 & 14 & 15 \\
\hline Male & 0.9 & 1.2 & 1.5 & 1.2 & 1.0 & 1.5 & 1 & 1.3 & 1.1 & 1.2 & 1.1 & 1.2 & 0.9 & 1.0 & 1.4 \\
\hline Female & 2.0 & 2.5 & 2.5 & 2.5 & 2.1 & 2.5 & 2.2 & 2.4 & 2.5 & 2.4 & 2.0 & 2.3 & 2.5 & 2.1 & 2.1 \\
\hline
\end{tabular}




\section{Ridge Count}

Ridge count is the number of ridges occured in a particular region of a particular section of the fingerprint. The result of the Ridge count is shown in the table below, and it shows that the males have a slightly higher ridge count than the females.

TABLE 5: Rigde COUNTS

\begin{tabular}{|c|c|c|}
\hline $\mathbf{S} / \mathbf{N}$ & Males & Females \\
\hline 1 & 14.642 & 13.661 \\
\hline 2 & 14.352 & 13.781 \\
\hline 3 & 14.253 & 12.978 \\
\hline 4 & 13.948 & 13.465 \\
\hline 5 & 14.645 & 13.875 \\
\hline 6 & 16.473 & 13.667 \\
\hline 7 & 14.731 & 13.657 \\
\hline 8 & 14.532 & 13.898 \\
\hline 9 & 14.572 & 13.675 \\
\hline 10 & 14.493 & 13.643 \\
\hline 11 & 14.343 & 13.794 \\
\hline 12 & 14.637 & 13.103 \\
\hline 13 & 15.362 & 13.133 \\
\hline 14 & 14.546 & 12.981 \\
\hline 15 & 14.691 & 13.408 \\
\hline
\end{tabular}

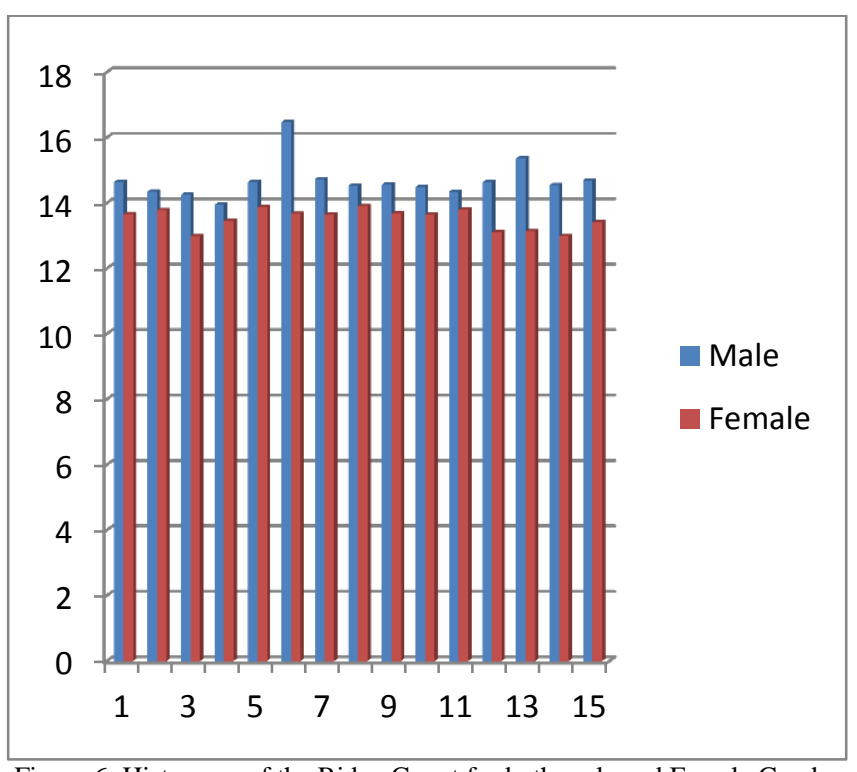

Figure 6: Histogram of the Ridge Count for both male and Female Gender made

From the results above, three observations can rightly be

1. The females have a higher ridge thickness to valley thickness ratio than the males.
2. The Males has a slightly higher ridge count than the females.

3. There is no particular relationship between the age of subjects and their fingerprint pattern, as it does not change (only as a result of accident or mutation)

The network has been trained and tested for a number of fingerprint image of different sex and age range. Since the implementation of the software is open and the program code is scalable, the inclusion of more number of fingerprint images from different people is straight forward.

The necessary steps are preparing the sequence of input symbol images in a single image file (*.bmp [bitmap] extension). The application will provide a file opener dialog for the user to locate the *.net network file and will load the corresponding training file by itself.

Fingerprint image size is $10 * 10$ in dimension. Use of any other size is also possible by preparing the input/desired output set as explained. The application can be operated with fingerprint images as small as $10 * 10$ dimensions in size.

\section{CONCLUSION AND RECOMMENDATION}

This research works have presented a model towards the determination of gender through the fingerprint information. The technical approach followed in processing input images, detecting graphic symbols, analyzing and mapping the fingerprint and training the network for a set of desired corresponding image to the input images have been discussed. Multi-Layer Perceptron (MLP) model technique was used, and results were obtained for age $\&$ gender, Ridge Thickness To Valley Thickness Ratio \& Ridge Count for trained finger prints sampled. We observed that the females have a higher ridge thickness to valley thickness ratio compare to males. The Males has a slightly higher ridge count compare to females, there is no particular relationship between the age of subjects and their fingerprint pattern, as it does not change (only as a result of accident or mutation)

\section{RECOMMENDATION}

Further research is necessary to develop feature extraction approaches that can reliably and consistently extract a set of features that provide rich information to age, paternalism e.t.c.

\section{REFRENCES}

[1] Acree M.A. (1999) Is there a gender difference in fingerprint ridge density? Forensic Science International, 102: 35-44.

[2] Badawi Ahmed, Mohamed Mahfouz, RimonTadross, Richard Jantz. (2008) Fingerprint-Based Gender Classification.

[3] Capelli R, Maltoni D. and Ferrara M. (2006) The quality of fingerprint scanners and the impact on the Accuracy of Fingerprint Recognition Algorithms In Proceedings of Multimedia Content Representation, Classification and Security (MRSC 2006), pages 10,16.

[4] Caplan R.M and J.ADermatol, 1990. How fingerprint came into use for personal identification. Graw-Hill Press.

[5] Cote Karine,. Earls Christopher M, and . Lalumiere Martin L. (2002) "Birth Order, Birth Interval, and Deviant Sexual Preferences Among Sex Offenders." Sexual Abuse: A Journal of Research and Treatment, Vol. 14 , No. 1.

[6] Drets. G and H. Liljenstrom, "Fingerprint Sub-Classification, (1982) A Neural Network Approach," Intelligence Biometric Techniques In Fingerprint and Face Recognition, PP. 109-134, 1999. Galton F. Finger Prints. Macmillian London 
[7] Gu J., Zhou J., and Yang C. (2006) Fingerprint Recognition by combining global structure and local clues. IEEE Transactions on Image Processing, 15(7): 1924\{1964.

[8] Gungadin, S. (2007) Sex Determination from Fingerprint Ridge Density. Internet Journal of Medical Update, 2: Jul-Dec 2(2).

[9] Gurney, K. (1997). An Introduction to Neural Networks London: Routledge.

[10] Hall, J. A. Y. and Kimura D.( 1994) "Dermatoglyphic Asymmetry and Sexual Orientation in Men." ,Behavioral Neuroscience, 108, 1203-1206,

[11] Haykin, S. (1999) Neural Networks: A Comprehensive Foundation, Prentice Hall, ISBN 0-13-273350-1

[12] Hicklin R. Austin, Christopher L. Reedy, (2002) "Implications of the IDENT/IAFIS Image Quality Study for Visa Fingerprint Processing", Mitertek Systems (MTS).

[13] Hong L., Prabhakar. S., Jain. A. K., and Pankanti. S., 'Filterbank-Based Fingerprint Matching," IEEE Transactions of Image Processing, Vol. 9:5, PP. 846-859, 2000.

[14] Jain A.K. Maltoni D. Maio D. and Prabhakar S. (2003) Handbook of Fingerprint Recognition. Springer, New York.

[15] Kralik M., Novotny V. (2003) Epidermal Ridge Breadth: An Indicator of Age and Sex in Paleodermatoglyphics. Variability and Evolution. Vol-11; 5-30
[16] Lee C. Henry and Gaensslen E. Robert (2001) Advances of Fingerprint Technology. Elsevier Science.

[17] Mohamed.S., H. O. Nyongesa, and J Siddiqi (2000) "Automatic Fingerprint Identification System Using Fuzzy Neural Techniques, 'Proceedings of the International Conference on Artificial Intelligence, Volume 2 PP. 859-865, CSREA Press, Las Vegas.

[18] Neil Yager, Adnan Amin (2004) "Fingerprint classification: a review," Springer-Verlag London.

[19] Penrose L.S. (2001). Memorandum on Dermatoglyphic Nomenclature. Birth Defects Original Article Series, 4: 1-13.

[20] The Federal Bureau of Investigation (1984). The Science of Fingerprints: Classification and Uses. Technical Reports U.S Government Publication, Washington,DC.

[21] Wang Y, Hu J, Phillips D. A (2007) Fingerprint Orientation Model Based on 2D Fourier Expansion (FOMFE) and its application to Singular-Point Detection and Fingerprint Indexing. IEEE Trans Pattern Anal Mach Intell:;29(4):573-85.

[22] Wendt GG (1955) "ÜberweißeLinienimAbdruck der men schlichenFingerbeere.” Homo 6:180-188. 